\title{
Oseltamivir phosphate monotherapy ablates tumor neovascularization, growth, and metastasis in mouse model of human triple-negative breast adenocarcinoma
}

\author{
This article was published in the following Dove Press journal: \\ Breast Cancer:Targets and Therapy \\ 9 December 2014 \\ Number of times this article has been viewed
}

\author{
Fiona Haxho' \\ Stephanie Allison ${ }^{2}$ \\ Farah Alghamdi',3 \\ Lacey Brodhagen' \\ Victoria EL Kuta' \\ Samar Abdulkhalek ${ }^{1,4}$ \\ Ronald J Neufeld ${ }^{2}$ \\ Myron R Szewczuk' \\ 'Department of Biomedical and \\ Molecular Sciences, ${ }^{2}$ Department \\ of Chemical Engineering, Queen's \\ University, Kingston, ON, Canada; \\ ${ }^{3}$ The King Fahd Armed Forces \\ Hospital, Serology, Jeddah, Saudi \\ Arabia; ${ }^{4}$ Department of Molecular \\ Genetics, Lerner Research Institute, \\ Cleveland Clinic, Cleveland, OH, USA
}

Correspondence: Myron R Szewczuk Department of Biomedical and Molecular Sciences, Queen's University, Kingston, ON K7L 3N6, Canada

$\mathrm{Tel}+\mathrm{I} 6135332457$

Fax + I 613 5336796

Email szewczuk@queensu.ca
Background: Triple-negative breast cancers (TNBCs) lack the estrogen, progesterone, and epidermal growth factor (EGF) receptor-2 (HER2/neu) receptors. Patients with TNBC have typical high grading, more frequent relapses, and exhibit poorer outcomes or prognosis compared with the other subtypes of breast cancers. Currently, there are no targeted therapies that are effective for TNBC. Preclinical antitumor activity of oseltamivir phosphate (OP) therapy was investigated to identify its role in tumor neovascularization, growth, invasiveness, and long-term survival in a mouse model of human TNBC.

Methods: Live cell sialidase, water soluble tetrazolium, WST-1 cell viability, and immunohistochemistry assays were used to evaluate sialidase activity, cell survival, and the expression levels of tumor E-cadherin, N-cadherin, and host endothelial CD31+/PECAM-1 cells in archived paraffin-embedded TNBC MDA-MB-231 tumors grown in RAGxC $\gamma$ double mutant mice.

Results: OP, anti-Neu1 antibodies, and matrix metalloproteinase-9-specific inhibitor blocked Neu1 activity associated with EGF-stimulated TNBC MDA-MB-231 cells. OP treatment of MDA-MB-231 and MCF-7 cells and their long-term tamoxifen-resistant clones reproducibly and dose-dependently reduced the sialidase activity associated with EGF-stimulated live cells and the cell viability after 72 hours of incubation. Combination of $1 \mu \mathrm{M}$ cisplatin, 5-FU, paclitaxel, gemcitabine, or tamoxifen with OP dosages $\geq 300 \mu \mathrm{g} / \mathrm{mL}$ significantly reduced cell viability at 24,48 , and 72 hours when compared to the chemodrug alone. Heterotopic xenografts of MDAMB-231 tumors developed robust and bloody tumor vascularization in RAG2xC $\gamma$ double mutant mice. OP treatment at $30 \mathrm{mg} / \mathrm{kg}$ daily intraperitoneally reduced tumor vascularization and growth rate as well as significantly reduced tumor weight and spread to the lungs compared with the untreated cohorts. OP treatment at $50 \mathrm{mg} / \mathrm{kg}$ completely ablated tumor vascularization, tumor growth and spread to the lungs, with significant long-term survival at day 180 postimplantation, tumor shrinking, and no relapses after 56 days off-drug. OP $30 \mathrm{mg} / \mathrm{kg}$ cohort tumors expressed significantly reduced levels of human N-cadherins and host CD31+ endothelial cells with concomitant significant expression of E-cadherins compared to the untreated cohorts.

Conclusion: OP monotherapy may be the effective treatment therapy for TNBC.

Keywords: triple-negative breast cancer, chemoresistance

\section{Introduction}

Breast cancers that are basal-like tumors constitute $75 \%$ of triple-negative breast cancer (TNBC) classification, with unique clinical (eg, premenopausal age onset, high parity, prevalence in African-American and Hispanic women, visceral and brain metastases) and histological features (eg, grade 3, high proliferative rate, apoptotic cells, central necrosis, 
lymphocytic response, and glomeruloid microvascular proliferation). ${ }^{1}$ Unfortunately, this classification of TNBC includes $\sim 25 \%$ of breast cancer tumors that are not basal-like. Thus, patients incorrectly labeled as having estrogen receptor (ER) and progesterone receptor negative invasive disease are at risk of an incomplete diagnosis for an effective and possible life-saving therapy. Clinically, the therapy for TNBC is to use standard chemotherapeutics, but these treatments are associated with a high rate of relapse at local and systemic regions. This "good chemosensitivity-bad prognosis", often referred to as the triple-negative paradox, is the clinical feature of this type of breast cancer. ${ }^{1}$ To date, there are no targeted therapies that are effective for TNBC. The current state of the art for TNBC is eloquently reviewed by Rastelli et al. ${ }^{1}$

In the clinical setting, targeted therapies based on single agents like specific antibodies or small molecule inhibitors against receptor tyrosine kinase have failed because they do not meet the primary endpoint of improvement for overall survival of the patients. ${ }^{2}$ For TNBCs, there are no current data that can predict a significant correlation between the receptor tyrosine kinase status and the response rates to tyrosine kinase inhibitors. For example, targeted therapies include: 1) zaltrap (aflibercept) as an angiogenesis inhibitor for prostate cancer; 2) torisel (temsirolimus or CCI-779) as a rapamycin (mTOR) inhibitor for first-line renal cell carcinoma in combination with avastin (bevacizumab) and a second-line renal cell carcinoma following therapy with sutent (sunitinib); and 3) avastin (bevacizumab) as an angiogenesis inhibitor in addition to chemotherapy following surgery for triple-negative adjuvant breast cancer.

Here, we describe an alternate therapeutic approach for breast cancers classified as TNBC, which is based on our newly discovered signaling platform that regulates epidermal growth factor (EGF) receptors (EGFRs). ${ }^{3}$ EGF binding to its receptor induces a G-protein coupled receptor signaling process to activate matrix metalloproteinase-9 (MMP-9) and Neu1 sialidase. The report discloses a novel complex of neuromedin B G-protein coupled receptor, MMP-9, and Neul tethered to EGFR at the ectodomain of the receptor on the cell surface. Activated Neu1 specifically hydrolyzes $\alpha$-2,3-sialyl residues of the receptors, which facilitates the removal of steric hindrance between receptors, allowing subsequent kinase activation and cellular signaling. We have previously reported that an identical signaling paradigm is used by nerve growth factor TrkA receptors, ${ }^{4}$ insulin receptors, ${ }^{5}$ cell surface TOLL-like receptor- $4,{ }^{6-10}$ and intracellular TOLL-like receptor-7 and $-9 ;{ }^{11}$ all of these receptors are known to play major roles in tumorigenesis. In addition, we have found that oseltamivir phosphate (OP) targeted and inhibited the induction of Neu1 activity associated with these receptor activations. ${ }^{4,10,11}$ Furthermore, we have reported a new therapeutic approach using OP as an anticancer agent. ${ }^{3}$ Since Neu1 is involved as one of the key central players for EGFR signaling, preclinical molecular-targeting studies provide the proof-of-evidence for an effective OP therapy in the treatment of human pancreatic cancer growth and metastatic spread in heterotopic xenograft of tumors growing in RAGxC $\gamma$ double mutant mice. ${ }^{3}$ In addition, OP overcame the chemoresistance of pancreatic PANC1 cancer cells to cisplatin and gemcitabine alone or in combination in a dose-dependent manner, and disabled the cancer cell survival mechanism(s) against the chemotherapeutic drugs. ${ }^{12}$ Interestingly, the data in the report also provided additional confirmation for OP therapy in reversing epithelial-mesenchymal transition (EMT) associated with resistance to standard, clinical chemotherapeutics. Recently, we reported that silencing transcriptional factor snail in ovarian carcinoma cells ablated the abnormal robust and bloody tumor vascularization in $\mathrm{RAGxC} \gamma$ double mutant mice with a concomitant abolishment of tumor growth and metastatic spread to the lungs. ${ }^{13}$ Collectively, the data suggest another molecular level of a novel organizational signaling platform connecting the snail-MMP-9 signaling axis in amplifying the Neu1 sialidase and MMP-9 cross-talk in regulating EGFRs, tumor neovascularization, growth, and invasiveness.

The present report describes an alternate therapeutic approach for the treatment of TNBC. OP monotherapy ablates in a dose-dependent manner tumor neovascularization, growth, and metastasis in mouse model of human triple-negative breast adenocarcinoma.

\section{Materials and methods Cell lines}

MCF-7 (ATCC ${ }^{\circledast}$ HTB-22 ${ }^{\mathrm{TM}}$ ) and MDA-MB-231 (ATCC ${ }^{\circledR}$ HTB-26 ${ }^{\mathrm{TM}}$ ) are adherent epithelial adenocarcinomas obtained from the mammary gland, breast, which are derived from the metastatic pleural effusion site. MDA-MB-231 is a triplenegative, basal $B$ subtype, mesenchymal stem-like, invasive ductal carcinoma with BRAF, CDKN2A, KRAS, NF2, TP53, and PDGFRA mutations. ${ }^{14} \mathrm{MCF}-7$ is a non-triple negative human breast adenocarcinoma cell line. The cells were grown in culture media containing $1 \times$ Dulbecco's Modified Eagle's Medium (DMEM; Gibco, Rockville, MD, USA), conditioned medium, supplemented with $10 \%$ fetal calf serum (FCS; HyClone, Logan, UT, USA), and $5 \mu \mathrm{g} / \mathrm{mL}$ plasmocin ${ }^{\mathrm{TM}}$ (InvivoGen, San Diego, CA, USA) in a $5 \% \mathrm{CO}_{2}$ incubator at $37^{\circ} \mathrm{C}$. At $\sim 80 \%$ confluence, the cells were passaged at least five times before use in the experiments. 
MCF-7 and MDA-MB-231 cell lines resistant against $5 \mu \mathrm{M}$ and $10 \mu \mathrm{M}$ tamoxifen were established in culture to gradual increases in concentrations of the indicated drugs in $1 \times$ DMEM conditioned medium. After removing dead cells, the viable cells were maintained in culture at the indicated chemodrug concentration. At $\sim 80 \%$ confluence, cells were passaged in the same concentration of the chemotherapeutic agent for over 1 year. Stable MCF-7 and MDA-MB-231 resistant clones against $5 \mu \mathrm{M}$ and $10 \mu \mathrm{M}$ tamoxifen were used for the in vitro experiments.

\section{Reagents}

EGF (Sigma-Aldrich, St Louis, MO, USA), the natural ligand of the EGFR, was reconstituted in sterile $1 \times$ phosphatebuffered saline (PBS) at a stock concentration of $1 \mathrm{mg} / \mathrm{mL}$ and stored at $-20^{\circ} \mathrm{C}$. EGF concentrations to stimulate cells were $30-100 \mathrm{ng} / \mathrm{mL}$. Incubation times varied between experiments and thus are indicated.

cis-Diamineplatinum(II) dichloride (P4394; SigmaAldrich) was reconstituted in dimethyl sulfoxide (DMSO) to make a $27.7 \mathrm{mM}$ stock solution. Gemcitabine hydrochloride (G6423; Sigma-Aldrich) was reconstituted in $1 \times \mathrm{PBS}$ to make a 133.5 mM stock solution. 5-Fluorouracil (5-FU) (F6627; Sigma-Aldrich) was reconstituted in a mixture of $1 \mathrm{~mL}$ DMSO and $9 \mathrm{~mL} 1 \times$ PBS to make $2.31 \mathrm{mM}$ 5-FU stock. Paclitaxel from Taxus brevifolia, (T7402, Sigma-Aldrich), was reconstituted in DMSO to make $1.17 \mathrm{mM}$ stock. These stocks were further diluted in $1 \times$ DMEM conditioned medium to make various dosages of the chemotherapeutic agents to be used in in vitro experiments.

\section{Inhibitors}

OP $75 \mathrm{mg}$ capsules were reconstituted in sterile $1 \times$ PBS and centrifuged at $1,000 \mathrm{rpm}$ for 10 minutes to obtain OP in the supernatant as previously reported. ${ }^{12}$ The stock-extracted OP solution had a concentration of $15 \mathrm{mg} / \mathrm{mL}$. OP $(\sim 98 \%$ purity) was obtained from Hangzhou DayangChem Co, Ltd (Hangzhou City, People's Republic of China). Cell culture in $1 \times$ DMEM conditioned medium containing different concentrations of OP $(200-800 \mu \mathrm{g} / \mathrm{mL})$ were used for the in vitro and in vivo experiments. MMP-9 inhibitor (CAS1177749-58-4) was obtained from Calbiochem-EMD Chemicals Inc. (half maximal inhibitory concentration $=5 \mathrm{nM}$ ).

\section{Primary antibodies}

Neutralizing antibodies were used to inhibit sialidase function: rabbit anti-human Neu1 immunoglobulin G (IgG) antibody (Santa Cruz Biotechnology, Santa Cruz, CA,
USA). Rabbit monoclonal anti-human E-cadherin antibody (Cell Signaling Technology, Inc., Danvers, MA, USA) was used at 1:400 dilution for immunohistochemistry according to the manufacturer's instructions. Rabbit monoclonal anti-human N-cadherin (Cell Signaling Technology, Inc.) was used at 1:200 dilution according to the manufacturer's instructions.

DyLight $^{\mathrm{TM}} 488$ donkey anti-rabbit IgG secondary antibody (Santa Cruz Biotechnology, Inc.) was used at $40 \mu \mathrm{g} / \mathrm{mL}$ to detect primary antibodies against human E- and N-cadherins in archived paraffin-embedded xenogafts of human MDAMB-231 tumors. DyLight ${ }^{\mathrm{TM}} 488$ rat monoclonal anti-mouse CD31/PECAM-1 antibody (Novus Biologicals Canada ULC, Oakville, ON, Canada) was used at a 1:300 dilution according to the manufacturer's instructions to detect mouse CD31+/PECAM-1 endothelial cells in the archived paraffinembedded xenogafts of MDA-MB-231 tumors.

\section{Sialidase assay in live cells}

Cells were grown on $12 \mathrm{~mm}$ circular glass slides in $1 \times$ DMEM conditioned medium in sterile 24-well tissue plates for 24 hours or until they reached $\sim 70 \%$ confluence as previously optimized in the live cell sialidase assay. ${ }^{8,10}$ After removing medium, 2'-(4-methylumbelliferyl)- $\alpha$-D$\mathrm{N}$-acetylneuraminic acid (4-MUNANA; Biosynth Intl.) substrate at $0.318 \mathrm{mM}$ in Tris-buffered saline, $\mathrm{pH} 7.4$, was added to each well alone (control), with EGF (30 ng/mL), or in combinations of EGF and inhibitors or neutralizing antibodies at the indicated concentrations. 4-MUNANA substrate is hydrolyzed by sialidase activity to give free 4-methylumbelliferone at fluorescence emission of $450 \mathrm{~nm}$, followed with an excitation at $365 \mathrm{~nm}$. Fluorescent images were taken after 1-2 minutes using Zeiss M2 Imager epifluorescent microscopy (EC PLnN 20×/0.5 DICII objective, 200× total magnification). The mean fluorescence surrounding the cells was quantified using the Image J program.

\section{Mouse model of human TNBC}

A mouse model of human TNBC that has a double mutation in the combining recombinase activating gene (RAG1) and common cytokine receptor $\gamma$ chain $(\mathrm{C} \gamma)$ (RAG1xCy) was used as previously described for human pancreatic cancer. ${ }^{3}$ The RAG1xC $\gamma$ double mutant mice on a non-obese diabetic (NOD.Cg-Rag1tm1Mom Il2rgtm1Wjl/SzJ; The Jackson Laboratory) genetic background are completely deficient in T-, B-, and natural killer-cells; show no spontaneous tumor formation; and exhibit normal hematopoietic parameters. ${ }^{15}$ A breeding colony of mice were generated by intercrossing 
and were maintained in specific pathogen-free isolators in the Animal Care Facility, Queen's University, Kingston, ON, Canada. All mice were kept under sterile conditions in microisolators equipped with autoclaved food and water. Experimental protocols using mice in these studies received approval from the Animal Care Committee, Queen's University. Mice between 6 and 8 weeks of age were used.

\section{Cancer cell implantation in RAGxC $\gamma$ double mutant xenograft mice}

MDA-MB-231 cells grown in $75 \mathrm{~cm}^{2}$ cell culture flasks at $80 \%$ confluence were resuspended into solution using TrypLE Express (Gibco) and washed in sterile saline. The cells in suspension were centrifuged for 3 minutes at $900 \mathrm{rpm}$, and the cell pellet suspended in sterile saline at a concentration of $5-10 \times 10^{6}$ cells $/ \mathrm{mL}$ for $0.5 \times 10^{6}$ cell implantation cutaneously into the right back flank of the mouse. There were four mice in each cohort of untreated, $30 \mathrm{mg} / \mathrm{kg} \mathrm{OP}$, and $50 \mathrm{mg} / \mathrm{kg}$ OP. Treatment with $30 \mathrm{mg} / \mathrm{kg}$ and $50 \mathrm{mg} / \mathrm{kg}$ of soluble OP in sterile saline were injected daily intraperitoneally starting at day 10 postimplantation, when the tumor volumes reached 10-20 $\mathrm{mm}^{3}$. For the $50 \mathrm{mg} / \mathrm{kg}$ OP cohort, the daily treatment regimen continued to day 111 , then once a week until day 124 , when the mice were taken off the drug treatment. The treatment regimen with OP was based on previously reported results on pancreatic $^{3}$ and ovarian ${ }^{13}$ cancer cells. Tumor volumes were measured twice a week and determined as

(width squared/2) $\times$ length

At the endpoints at day 180 or earlier due to skin lesions, mice were weighed and euthanized by cervical dislocation, and live necropsy tumor, liver, lung, pancreas, heart, and spleen were weighed. Archived paraffin-embedded tumor, liver, and lung necropsy tissues were used for hematoxylin and eosin staining and immunostaining for CD31+/PECAM-1 cells in tumor tissues, followed by microscopic analysis using a Zeiss Imager M2 fluorescence microscope.

\section{Immunohistochemistry}

The presence of the characteristic human epithelial marker, E-cadherin, and human mesenchymal marker, N-cadherin, in human MDA-MB-231 tumors was detected using immunohistochemistry and specific antibodies. Processed tumors were embedded in paraffin blocks following necropsy in each experiment. Microtome sections of tumor at $5 \mu \mathrm{m}$ thickness were deparaffinized, heated for 8 minutes in citrate buffer, and rinsed three times in $1 \times$ PBS, followed by blocking with $1 \%$ bovine serum albumin (Thermo Fisher Scientific) in $1 \times$ PBS overnight at $4{ }^{\circ} \mathrm{C}$. Deparaffinized and processed tumor sections $(5 \mu \mathrm{m})$ were immunostained with primary antibody for either $2 \mu \mathrm{g} / \mathrm{mL}$ rabbit anti-E- or anti-N-cadherin followed by Alexa Fluor ${ }^{\circledR} 488$ secondary donkey anti-rabbit IgG antibody. The stained cells were covered with Entellan ${ }^{\circledR}$ rapid mounting medium, and images were observed using a Zeiss Imager M2 fluorescence microscope at 200× magnification. Additional $5 \mu \mathrm{m}$ microtome sections of tumors were analyzed for mouse endothelial marker CD31/PECAM-1 using a 1:300 dilution of a $1 \mathrm{mg} / \mathrm{mL}$ stock of rat monoclonal antibody conjugated with DyLight-488 fluorochrome against mouse CD31/PECAM-1 (Novus Biologicals Canada ULC) and a Zeiss Imager M2 fluorescence microscope.

\section{WST-I assay}

The WST-1 assay is a standard measure of cell viability based on the reduction of a tetrazolium compound to a soluble derivative. ${ }^{16}$ The absorbance of the reaction at $420 \mathrm{~nm}$ is proportional to the number of living cells in culture. Cells at $80 \%-90 \%$ confluence were added to 96 -well microtiter plates at a density of 5,000 cells/well for 24 hours. They were treated with different concentrations of OP, chemodrugs, or left untreated as controls for 24,48 , and 72 hours. Absorbance readings were taken at $0,24,48$, and 72 hours by adding $10 \%$ WST-1 reagent (Roche Diagnostics, Laval-des-Rapides, QC, Canada) in $1 \times$ PBS to each well, followed by an incubation at $37^{\circ} \mathrm{C}$ for 2 hours before taking readings at the indicated time points. Cell viability as a percentage of control was illustrated as a bar graph using GraphPad Prism software (GraphPad Software, La Jolla, CA, USA). The following formula was used to determine cell viability as a percent of control for each time point after drug treatments:

([absorbance of cells in drug concentration]

$$
\begin{gathered}
-[\text { media absorbance }]) \\
([\text { absorbance of cells only }] \\
-[\text { media absorbance }])
\end{gathered}
$$

The "no treatment" WST-1 assay values were calculated for 24,48 , and 72 hours without drug treatment:

$$
\begin{gathered}
([\text { absorbance of cells at } 24 \text { hours }] \\
\frac{-[\text { media absorbance }])}{([\text { absorbance of cells only at } 0 \text { hours }]} \times 100 \\
-[\text { media absorbance }])
\end{gathered}
$$


The 0 hours refers to the sum of plated cells and the WST-1 assay reagent and readings taken after 2 hours.

\section{Statistical analysis}

Statistical analysis of data used GraphPad Prism software. Comparison of results were made by one-way ANOVA at 95\% confidence using Bonferroni's multiple comparison test or the unpaired $t$-test.

\section{Results}

\section{Neul sialidase activity is associated with EGF stimulation of TNBC MDA-MB-23 I cells}

Since the coexpression of EGFR and MMP-9 has prognostic value in cancer, ${ }^{17,18}$ and Neu1 and MMP-9 cross-talk regulates EGFRs in pancreatic ${ }^{3}$ and ovarian ${ }^{13}$ cancer cells, we investigated the molecular targeting potential of the Neu1-MMP-9 cross-talk platform in a TNBC MDA-MB231 cell line in vitro. We initially performed the sialidase assay on EGF-stimulated live cells as previously described by our group..$^{8,10,19}$ It is well known and characterized that MDA-MB-231 and MCF-7 breast cancer cells express the EGFRs. ${ }^{20,21}$ As shown in Figure 1A, EGF stimulation of live MDA-MB-231 cells induced sialidase activity as revealed in the periphery surrounding the cells using the fluorogenic sialidase-specific substrate, 4-MUNANA, which fluoresces at $450 \mathrm{~nm}$ due to the emission of 4-methylumbelliferone. The mean fluorescence of 50 multipoint replicates was quantified using the Image $\mathrm{J}$ software and is depicted in the bar graph. We also used specific neutralizing antibodies against

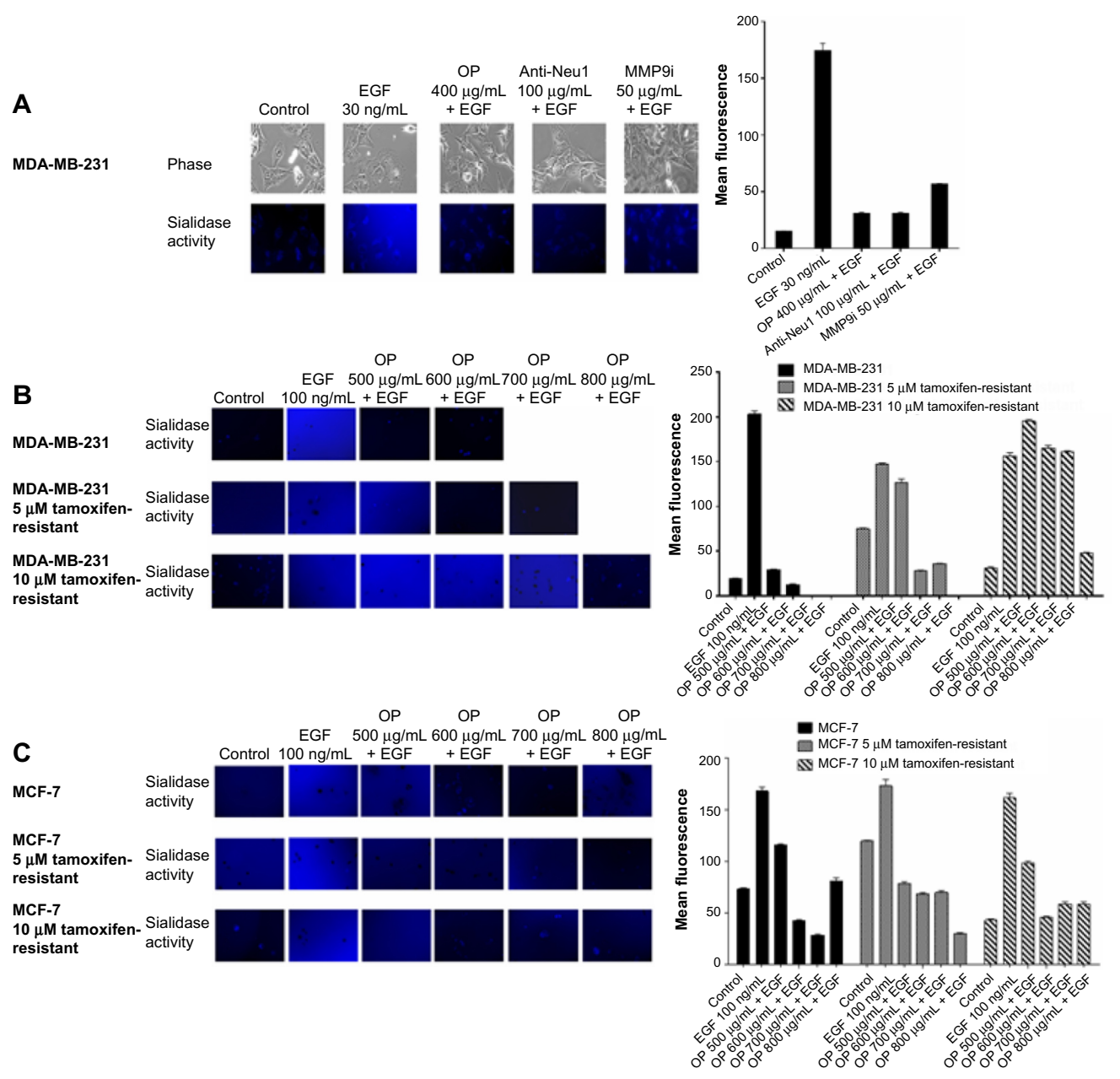

Figure I EGF induces sialidase activity in live (A) TNBC MDA-MB-23I cells, (B) MDA-MB-23I cells and its resistant clones against $5 \mu$ M and I0 $\mu$ M tamoxifen, and (C) MCF-7 cells and its resistant clones against $5 \mu \mathrm{M}$ and $10 \mu \mathrm{M}$ tamoxifen.

Notes: Cells were allowed to adhere on 12 mm circular glass slides in media containing $10 \%$ FCS for 24 hours. After removing media, 0.318 mM $4-M U N A N A$ substrate (2'[4-methlyumbelliferyl]- $\alpha-\mathrm{N}$-acetylneuraminic acid) in Tris-buffered saline, $\mathrm{pH} 7.4$, was added to live cells alone (control) or with EGF alone and in combination with OP, antiNeu I neutralizing antibodies, and specific inhibitor of MMP-9 at the indicated dosage. Fluorescent images were taken at I-2 minutes after adding substrate using Zeiss Imager M2 epi-fluorescence microscopy (20x objective). The mean fluorescence of 50 multipoint replicates was quantified using Image J software. The data are a representation of one out of three independent experiments showing similar results.

Abbreviations: EGF, epidermal growth factor; FCS, fetal calf serum; MMP-9, matrix metalloproteinase-9; OP, oseltamivir phosphate; TNBC, triple-negative breast cancer. 
the human Neul as well as the neuraminidase inhibitor OP and a specific inhibitor of MMP-9, all of which blocked the sialidase activity associated with EGF-treated live MDAMB-231 cells comparable to the levels of no EGF-treated controls. The anti-Neu1 antibody used is specific for the epitope corresponding to amino acids 116-415 mapping at the C-terminus of Neul of human origin. It also detects Neu1 of mouse, rat, and human origin. The data depicted in Figure $1 \mathrm{~A}$ are consistent with our previous reports for EGFRs in pancreatic ${ }^{3}$ and ovarian ${ }^{13}$ cancer cells.

In addition, we generated long-term (1 year) resistant clones of MDA-MB-231 and MCF-7 against $5 \mu \mathrm{M}$ and $10 \mu \mathrm{M}$ tamoxifen. With TNBC survival mechanisms against chemotherapeutics, the effects may be in large part manifested by the compensatory action of other downstream signaling molecules as described for the AXL and EGFR inhibitors. ${ }^{22}$ Martin et al have described in detail the current state of multidrug resistance in breast cancer, including the molecular mechanisms that contribute to tamoxifen resistance. ${ }^{23}$ Here, we hypothesized that tamoxifen-resistant MDA-MB-231 and MCF-7 clones at $5 \mu \mathrm{M}$ and $10 \mu \mathrm{M}$ may have a compensatory action(s) on other signaling pathways. In the presence of OP, the cancer cell survival mechanism(s) against the chemotherapeutic agents may be disabled and become more sensitive to the chemodrugs, as we have previously reported. ${ }^{12}$ As shown in Figure $1 \mathrm{~B}$ and $\mathrm{C}$, EGF stimulation of live tamoxifen-resistant MDA-MB-231 and MCF-7 cells induced sialidase activity. OP monotherapy dose-dependently blocked the sialidase activity associated with EGF-treated live cells comparable to the levels of no EGF-treated controls. It is noteworthy that the $10 \mu \mathrm{M}$ tamoxifen-resistant MDAMB-231 cells required a higher dosage of OP to block sialidase activity associated with EGF-stimulated cells compared to the $5 \mu \mathrm{M}$ tamoxifen and to the parental cells. To explain these latter data, it is proposed that long-term resistance against tamoxifen may have upregulated in a stoichiometric manner several other signaling pathways to compensate for the level of tamoxifen in the growth medium.

\section{Viability of MCF-7 and MDA-MB-23 I and their tamoxifen-resistant clones when treated with OP at different doses using the WST-I assay}

To test the in vitro effects of OP treatment on the cell viability of MCF-7 and MDA-MB-231 and their corresponding tamoxifen-resistant clones, we performed the WST-1 cell proliferation assay ${ }^{16}$ using various concentrations of tamoxifen or OP for 24,48 , and 72 hours as optimally predetermined.
Cell viability as a percentage of control \pm standard error of the mean of triplicate values was determined based on the reduction of a tetrazolium compound to the soluble form. The data shown in Figure $2 \mathrm{~A}$ and $\mathrm{B}$ indicate that the treatment of MCF-7 and MDA-MB-231 cells with tamoxifen dosedependently decreased the cell viability (as a percentage of untreated control), with a lethal dose to kill $50 \%$ of viable cells of $9 \mu \mathrm{M}$ for MCF-7 (Figure $2 \mathrm{~A}$ ) and $15 \mu \mathrm{M}$ for MDAMB-231 (Figure 2C) after 72 hours of incubation. We also tested the in vitro effects of OP treatment on cell viability using the tamoxifen-resistant MCF-7 and MDA-MB-231 cell clones. The data shown in Figure $2 \mathrm{~B}$ and $\mathrm{D}$ indicate that OP treatment reproducibly and dose-dependently, markedly decreased the cell viability (as a percentage of untreated control) for the tamoxifen-resistant clones when compared to the parental MCF-7 and MDA-MB-231 cell lines.

The viability of MDA-MB-231 cells following treatment with different dosages of OP in combination with $1 \mu \mathrm{M}$ of either cisplatin, 5-FU, paclitaxel, gemcitabine, or tamoxifen was compared with that of the chemodrug alone. The data in Figure 3 show that for the combination of cisplatin, 5-FU, paclitaxel, gemcitabine with OP dosages $\geq 300 \mu \mathrm{g} / \mathrm{mL}$ significantly reduced cell viability at 24,48 , and 72 hours when compared to the cell viability after single chemodrug treatment. In contrast, the combination of tamoxifen with OP at $800 \mu \mathrm{g} / \mathrm{mL}$ significantly reduced cell viability at 24 , 48 , and 72 hours.

\section{OP monotherapy dose-dependently ablates tumor vascularization, growth, and invasiveness in heterotopic xenografts of TNBC MDA-MB-23 I cells in RAGxC $\gamma$ double mutant mice}

The preclinical in vivo antitumor activity of OP was investigated in the RAGxC $\gamma$ double mutant mouse model of human TNBC MDA-MB-231 cells. The RAGxC $\gamma$ double mutant mouse lacks mature T- and B-cells, functional natural killer-cells, and is deficient in cytokine signaling, leading to better engraftment of human cells than any other published mouse strain. ${ }^{3}$ As previously demonstrated for pancreatic epithelial carcinoma cell line, ${ }^{3}$ the hypothesis is that OP monotherapy prevents the in vivo growth and spread of tumors in the heterotopic xenograft mouse model of human TNBC. MDA-MB-231 cells at $0.5 \times 10^{6}$ cells in $0.2 \mathrm{~mL}$ were implanted cutaneously in the right back flank of these mice. Twice a week, following implantation of the cancer cells, each mouse was monitored for tumor volume growth at the site of implantation, and body weight and condition were 


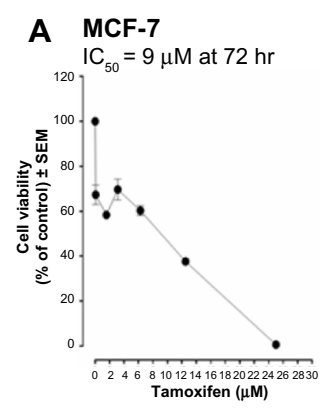

C MDA-MB-231 $\mathrm{IC}_{50}=15 \mu \mathrm{M}$ at $72 \mathrm{hr}$

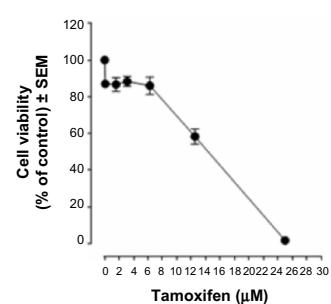

Tamoxifen ( $\mu \mathrm{M})$

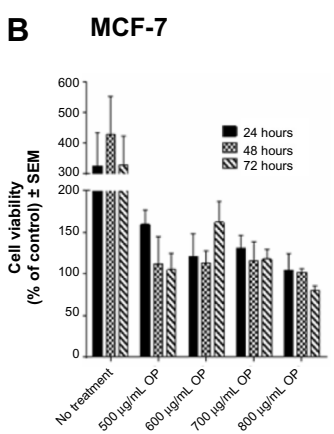

D MDA-MB-231

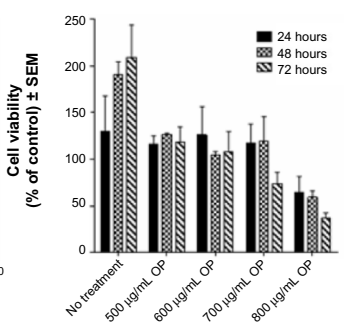

MCF-7

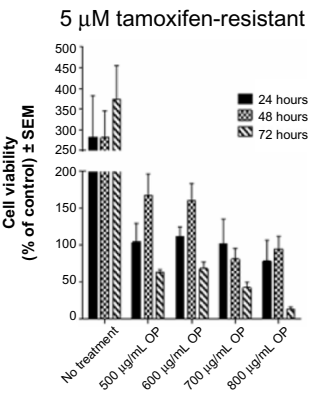

MDA-MB-231

$5 \mu \mathrm{M}$ tamoxifen-resistant

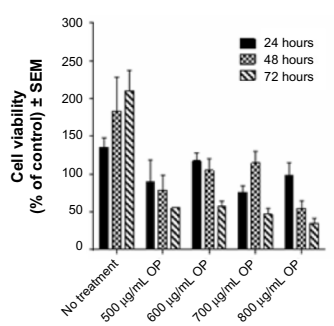

MCF-7

$10 \mu \mathrm{M}$ tamoxifen-resistant

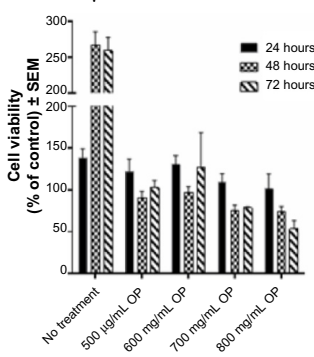

MDA-MB-231

$10 \mu \mathrm{M}$ tamoxifen-resistant

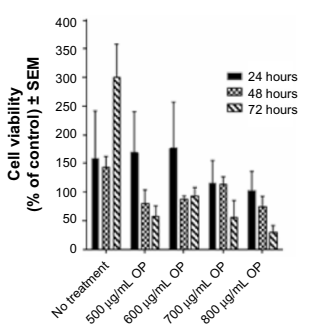

Figure 2 Cell viability of (A) MCF-7 and (C) MDA-MB-23I cells treated with tamoxifen at indicated doses, (B) MCF-7 and (D) MDA-MB-23I cells and their resistant clones against $5 \mu \mathrm{M}$ and $10 \mu \mathrm{M}$ tamoxifen treated with OP at indicated doses using the WST-I assay.

Notes: Cells were incubated in 96 -well plates (5,000 cells/well) and allowed to adhere for 24 hours in I× DMEM media containing $10 \%$ FCS. The media were replaced with fresh DMEM media containing 5\% FCS with or without various concentrations of tamoxifen or OP for indicated time periods. Cell viability was expressed as a percent of control \pm SEM of triplicate values. The data are a representation of one out of three independent experiments showing similar results. LD 50 value is given as $\mu M$ of drug concentration as determined by WST-I assay after 72 hours for the indicated cell lines.

Abbreviations: DMEM, Dulbecco's Modified Eagle's Medium; FCS, fetal calf serum; $\mathrm{IC}_{50}$, half maximal inhibitory concentration; $\mathrm{LD}_{50}$, lethal dose to kill $50 \%$ of viable cells; OP, oseltamivir phosphate; SEM, standard error of the mean.

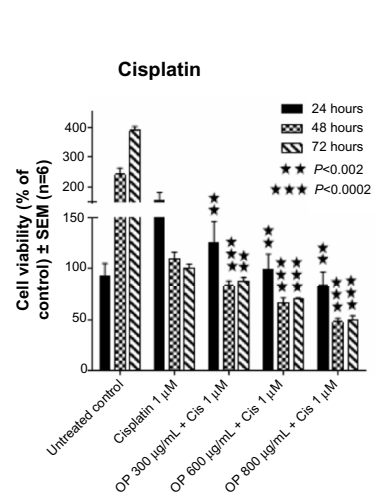

MDA-MB-231
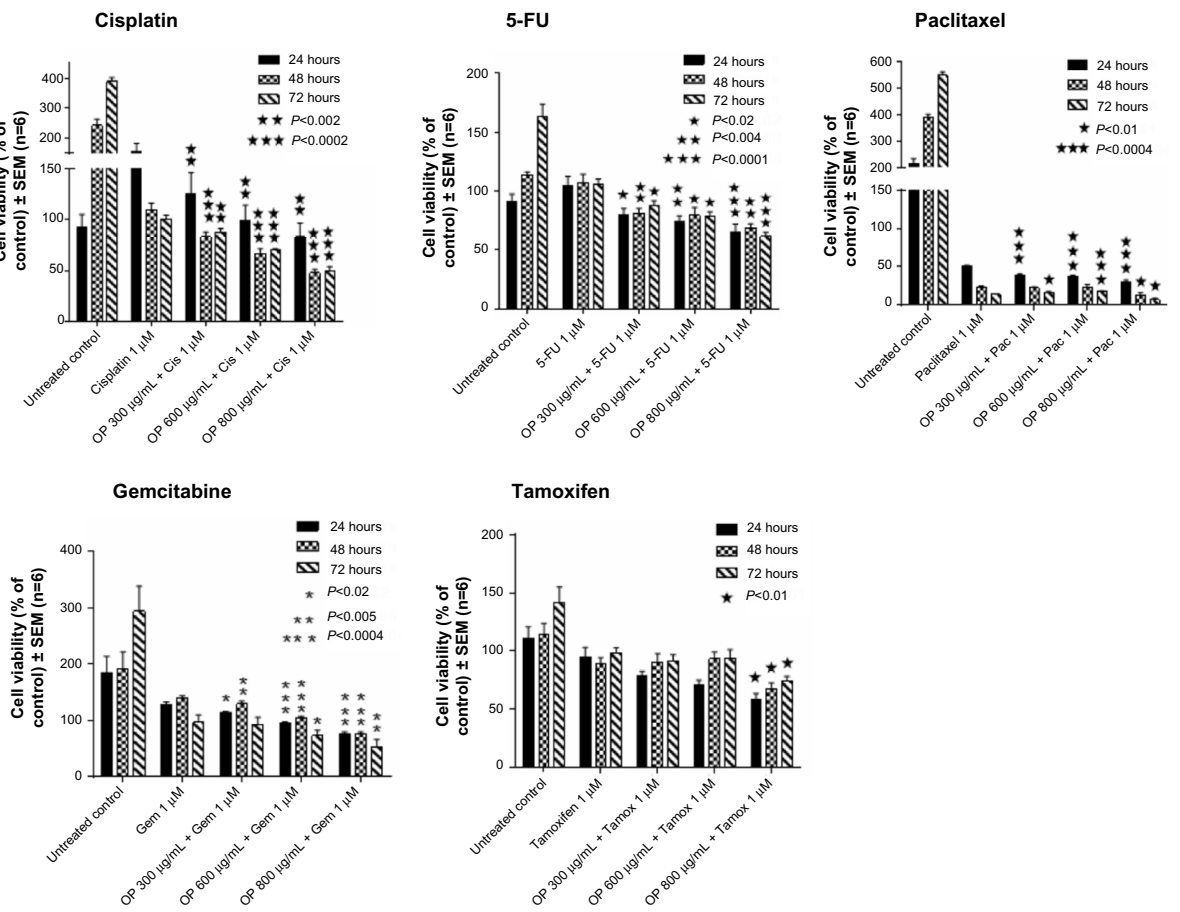

Figure 3 Cell viability of MDA-MB-23I cells treated with OP at indicated doses in combination with I $\mu$ M of either cisplatin, 5-FU, paclitaxel, gemcitabine, or tamoxifen using the WST-I assay.

Notes: Cells were incubated in 96-well plates (5,000 cells/well) and allowed to adhere for 24 hours in I×DMEM media containing $10 \%$ FCS. The media were replaced with fresh DMEM media containing $5 \%$ FCS with or without various concentrations of OP or chemodrugs for 24,48 , and 72 hours as predetermined optimally. Cell viability was expressed as a percent of control \pm SEM of three independent experiments. Statistical analysis was carried out using GraphPad Prism, and results were compared by unpaired $t$-test. Abbreviations: 5-FU, 5-fluorouracil; DMEM, Dulbecco's Modified Eagle's Medium; FCS, fetal calf serum; OP, oseltamivir phosphate; SEM, standard error of the mean. 
scored. All of the experimental mice showed no loss of body weight, and body condition scoring was normal until they developed skin lesions. Scoring the body condition of rodents is a noninvasive method for assessing health and establishing endpoints for adults where body weight is not a viable monitoring tool. For heterotopic implantation of MDA-MB-231 cells, mice developed skin lesions due to the abnormal tumor vascularization, which was the end point for body condition scoring. The data in Figure 4A show live tumors with skin lesions for each mouse (labeled A1, A2, and A4 for untreated control, B1-4 for OP $30 \mathrm{mg} / \mathrm{kg}$, and $\mathrm{C} 1$ and $\mathrm{C} 3$ for OP $50 \mathrm{mg} / \mathrm{kg}$ ) and live necropsy tumors with an unexpected, abnormal, robust, and bloody tumor vasculature at day 42 or earlier postimplantation of MDAMB-231 cells. Due to the abnormal tumor vasculature, we also immunostained paraffin-embedded tumors from each mouse for host endothelial cell marker CD31/PECAM-1. There was an extensive migration of host CD31+ cells to the tumors for the untreated cohort but markedly reduced levels for the $30 \mathrm{mg} / \mathrm{kg}$ OP-treated cohort (Figure 4B). For the $50 \mathrm{mg} / \mathrm{kg}$ OP cohort, there were no tumors at day 180 postimplantation. As expected, the necropsy tumors from the $30 \mathrm{mg} / \mathrm{kg}$ OP-treated cohort revealed significantly high levels of tumor E-cadherin with concomitant significantly reduced N-cadherin levels (Figure 4B).

Treatment with $30 \mathrm{mg} / \mathrm{kg}$ and $50 \mathrm{mg} / \mathrm{kg}$ of soluble OP in sterile saline with daily injections intraperitoneally at day 10 postimplantation when the tumor volume reached $10-20 \mathrm{~mm}^{3}$ attenuated the aggressive tumor vascularization with skin lesions (Figure 4C) and the tumor growth (Figure 4D). The treatment regimen with OP was based on previously reported results on pancreatic $^{3}$ and ovarian ${ }^{13}$ cancer cells. It is proposed that OP

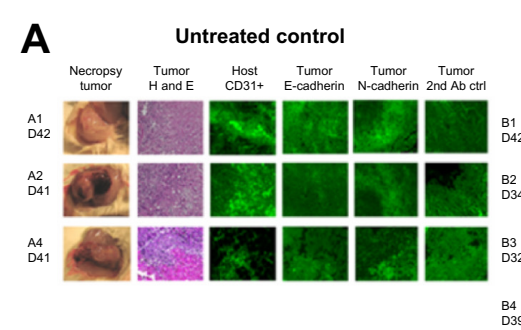

C

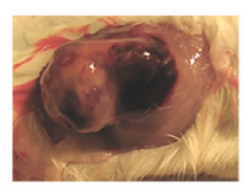

D

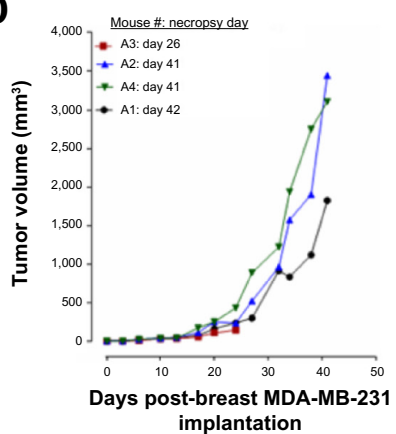

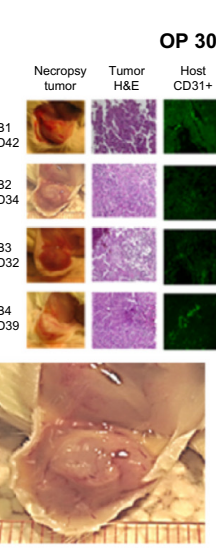

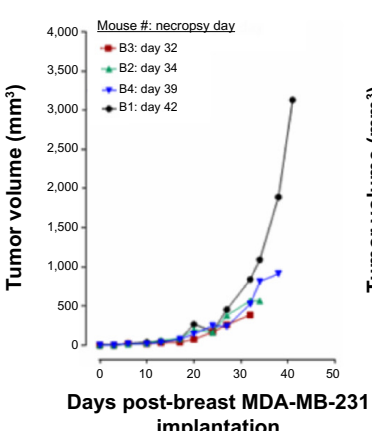

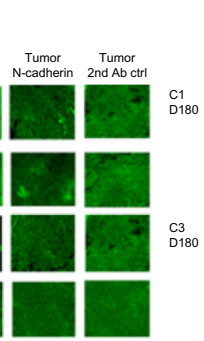
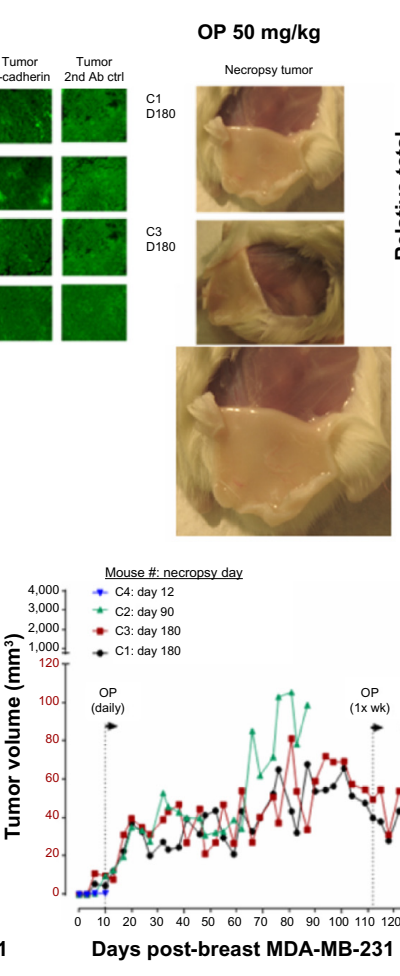

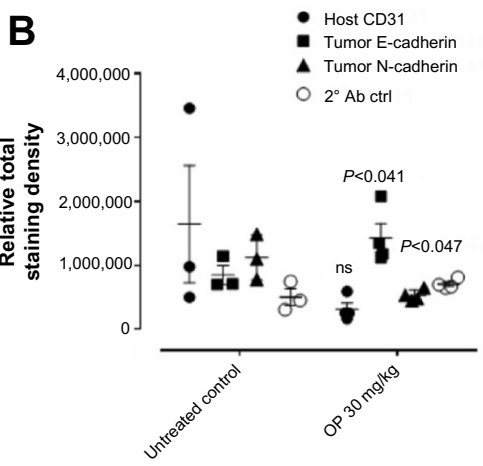

E

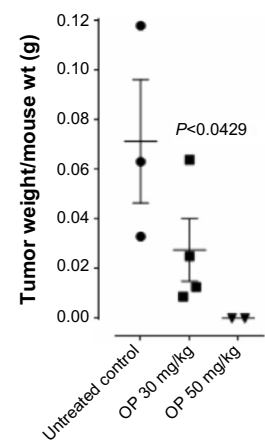

Days post-breast MDA-MB-231 implantation

Figure 4 OP treatment of RAGxC $\gamma$ double mutant mice bearing heterotopic xenograft of MDA-MB-23I tumors.

Notes: Cells at $0.5 \times 10^{6}$ in $0.2 \mathrm{~mL}$ were implanted cutaneously in the right back flank of mice. Twice a week following implantation of the cancer cells, each mouse was monitored for tumor volume ([width squared/2] $\times$ length) at the site of implantation. Mice were treated with $30 \mathrm{mg} / \mathrm{kg}$ and $50 \mathrm{mg} / \mathrm{kg}$ of OP in sterile saline ip daily at day 10 postimplantation, when the tumor volume reached $\sim 10-20 \mathrm{~mm}^{3}$. (A) Necropsy tumors, H\&E staining of tumors, paraffin-embedded tumor sections (5 $\left.\mu \mathrm{m}\right)$ on glass slides were processed for immunohistochemistry using primary DyLight 488-conjugated rat monoclonal anti-mouse CD3I/PECAM-I antibody, primary anti-E-cadherin, and $\mathrm{N}$-cadherin antibodies, followed with polyclonal goat anti-rabbit Alexa Fluor ${ }^{\circledR} 488$ secondary antibody in I\% BSA in PBS blocking solution and Entellan ${ }^{\circledR}$ rapid mounting medium. Background control (2nd Ab ctrl) sections were prepared without the primary antibodies. Stained tissue sections were photographed using an AxioCamMRm3-2 fluorescence camera attached to a Zeiss Imager M2 fluorescence microscope at 200× magnification. Images are representative of at least five fields of view from two tumor sections. (B) Quantitative analysis was done by assessing the density of tumor staining corrected for background in each panel using Corel Photo Paint 8.0 software. Each bar in the figure represents the mean $( \pm$ SEM) corrected density of tumor staining within the respective images; (C) Enlarged visualized image of live necropsy tumors; (D) Tumor growth rates for individual mice (mouse label AI, A2, and A4 for the control cohort; $\mathrm{BI}-4,30 \mathrm{mg} / \mathrm{kg} \mathrm{OP}$ cohort; and Cl and C3, $50 \mathrm{mg} / \mathrm{kg}$ cohort); (E) Mean $\pm \mathrm{SEM}$ of live necropsy tumor weight per mouse body weight; Statistical analysis was carried out using GraphPad Prism, and results were compared by unpaired $t$-test.

Abbreviations: BSA, bovine serum albumin; H\&E, hematoxylin and eosin; ip, intraperitoneally; ns, not significant; OP, oseltamivir phosphate; PBS, phosphate-buffered saline; SEM, standard error of the mean. 
treatment regimen for cancers with robust tumor vascularization requires higher doses for attenuating tumor growth.

For the $50 \mathrm{mg} / \mathrm{kg}$ OP cohort, daily injections of OP continued to day 111 postimplantation, followed by $1 \times$ weekly injections, and off OP treatment at day 124 until the end point of the experiment at day 180 . The data revealed tumor shrinking with no relapse. Live tumor weight per mouse body weight indicated a significant reduction for the OP $30 \mathrm{mg} / \mathrm{kg}$ cohort at days 32-42 (Figure 4E) compared to the untreated cohort. There were no visible tumors for the $50 \mathrm{mg} / \mathrm{kg}$ OP cohort at day 180. In addition, the survival rate of the $50 \mathrm{mg} / \mathrm{kg}$ OP-treated cohort was significant compared to the untreated control group (Figure 5A). The daily dosage of OP injections had no effect on the weights of the pancreas, heart, and liver per mouse body weight, but there was a marked decrease in the weight of the spleen per mouse body weight for the $50 \mathrm{mg} / \mathrm{kg}$ OP treatment (Figure 5B). These latter data are consistent with other reported results with patients with breast cancer where a reduction in spleen size was prognostic indicator. ${ }^{24-27}$ It is noteworthy that women in the weight category of less than $60 \mathrm{~kg}$ at diagnosis compared with those having the highest category of $79 \mathrm{~kg}$ revealed a 2.5 -fold increased risk of dying from breast cancer (hazard ratio, 2.54 [95\% confidence interval, 1.08-6.00]; trend $P=0.02) .{ }^{28}$

Live necropsy lungs (Figure 6A) showed no visible tumor nodules. There were no tumor nodules nor metastatic clusters of MDA-MB-231 cancer cells in the liver for each of the cohorts (data not shown). The daily dosage of $30 \mathrm{mg} / \mathrm{kg}$ and $50 \mathrm{mg} / \mathrm{kg}$ OP treatment intraperitoneally, significantly attenuated the metastatic spread of MDA-MB-231 breast cancer cells to the lungs (Figure 6B) compared to the extensive metastatic clusters of cancer cells in the lungs for the untreated cohort. OP treatment had no adverse effects on the lungs as indicated by lung weight per mouse body weight (Figure 6C). This lack of metastatic spread of the MDA-MB-231 cancer cells to the lung following OP treatment is dose-dependent on the treatment regime. The lack of invasiveness due to OP treatment may be due in part to a disruptive tumor vasculature development (eg, reduced host CD31+ endothelial cell migration) or a decreased expression of $\mathrm{N}$-cadherin with a concomitant increase in E-cadherin (Figure 4).

\section{Discussion}

Clinically, TNBC is insensitive to most of the effective therapies available for breast cancer treatments. ${ }^{29,30}$ For example, they include the HER2-targeted therapy such as Herceptin (trastuzumab) as well as tamoxifen or the aromatase inhibitors. These findings suggest that the growth of the cancer is not supported by the hormones estrogen and progesterone, nor by the presence of HER2 receptors. Combination chemotherapy using a metronomic dosage schedule is the standard therapy for early-stage TNBC. ${ }^{29}$ A prospective analysis of 1,118 patients who received
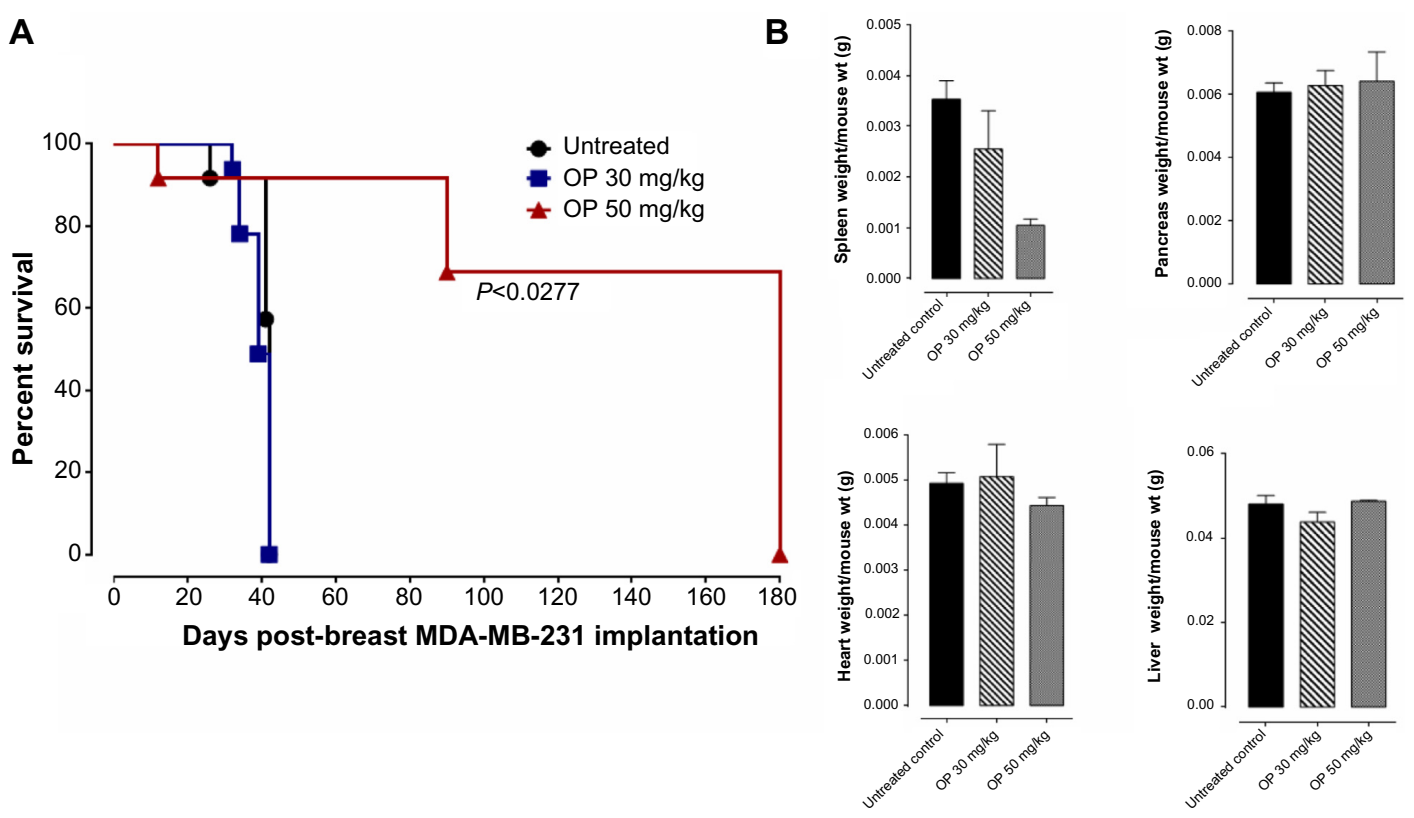

Figure 5 (A) Percent survival of indicated cohorts of mice taken from Figure 4D and (B) mean \pm SEM of live necropsy spleen, pancreas, heart, and liver weight per mouse body weight for each of the cohorts in Figure 4.

Note: Statistical analysis was performed using the Log-rank (Mantel-Cox) test. Abbreviations: OP, oseltamivir phosphate; SEM, standard error of the mean. 
A

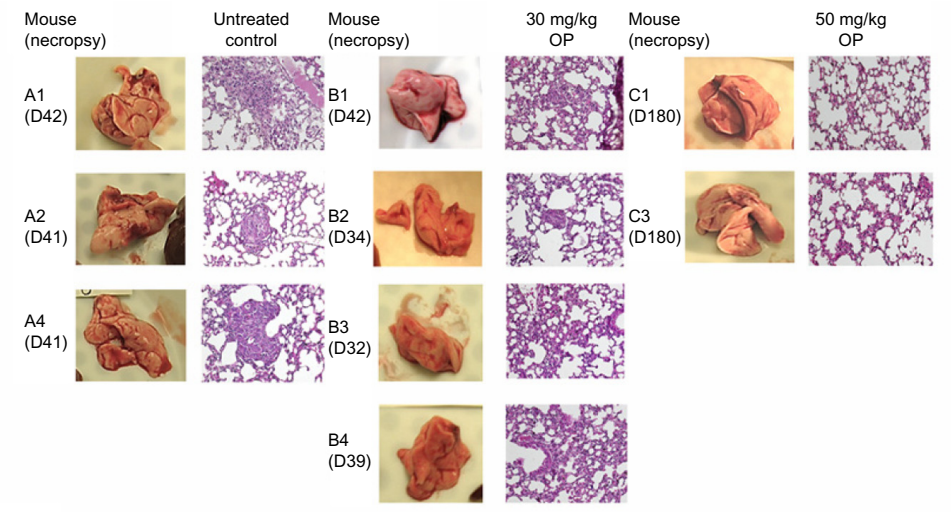

A4

B2
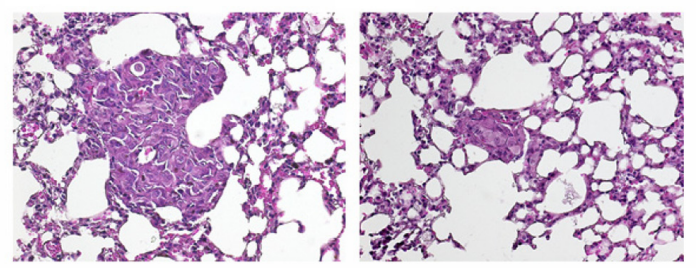

C3

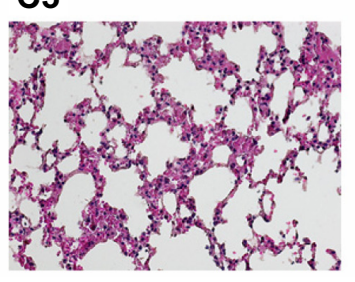

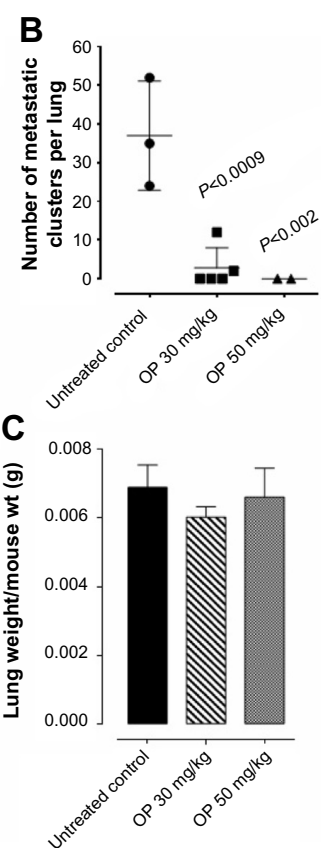

Figure 6 (A) H\&E staining of necropsy lung for number of metastatic clusters per lung (B) in paraffin-embedded tissues taken from xenograft $A 2780$ tumor-bearing RAGx $\mathrm{C}$ double mutant mice.

Notes: Mice were implanted with $0.5 \times 10^{6}$ MDA-MB-23I TNBC cells cutaneously on the rear back flank, and OP treatment began daily (ip) I0 days postimplantation, when tumors reached $10-20 \mathrm{~mm}^{3}$. Paraffin-embedded tissue sections $(5 \mu \mathrm{m})$ on glass slides were processed for H\&E staining for each mouse necropsied at indicated necropsy day postimplantation. Stained tissue sections were photographed using AxioCam MRc5 digital color camera attached to a Zeiss Imager M2 fluorescence microscope at 400X magnification. Images are representative of at least five fields of view from two tissue sections. (B) Metastatic lung clusters as representative in the insert were microscopically counted per tissues sections $(5 \mu \mathrm{m})$ and plotted in the graph. Statistical analysis was carried out using GraphPad Prism and results were compared by unpaired $t$-test. (C) Mean \pm SEM of live necropsy lung weight per mouse body weight for each of the cohorts.

Abbreviations: H\&E, hematoxylin and eosin; ip, intraperitoneally; OP, oseltamivir phosphate; SEM, standard error of the mean; TNBC, triple-negative breast cancer.

neoadjuvant chemotherapy, of whom 255 (23\%) had TNBC, indicated that patients with TNBC had higher pathologic complete response rates compared with non-TNBC patients ( $22 \%$ versus $11 \% ; P=0.034) .{ }^{30}$

In our studies, the data indicate that both MDA-MB-231 and non-TNBC MCF-7 cells developed resistance against $5 \mu \mathrm{M}$ and $10 \mu \mathrm{M}$ of tamoxifen for over 1 year. At least for the non-TNBC cells, it has been reported that cross-talk between ER, HER-2, p38, and ERK may contribute to tamoxifen resistance. ${ }^{31}$ In another report, tamoxifen was shown to behave as an estrogen agonist in breast cancer cells that express high levels of AIB1 (amplified in breast cancer-1) and HER2, resulting in de novo resistance against tamoxifen. ${ }^{32}$ In addition, the study had demonstrated that gefitinib, an inhibitor of EGFR tyrosine kinase, by binding to the adenosine triphosphate-binding site of the enzyme, eliminated tamoxifen's agonist effects and restored its antitumor activity both in vitro and in vivo in MCF-7/HER2-18 cells. ${ }^{32}$ Unfortunately, in another study, 25\%-30\% of patients with EGFR-activating mutations acquired resistance to gefitinib. ${ }^{33}$ The data in the report also showed that hepatocyte growth factor, a ligand of MET oncoprotein, facilitated the process of gefitinib resistance of lung adenocarcinoma cells, with EGFR-activating mutations, by restoring the phosphatidylinositol 3-kinase/Akt signaling pathway via phosphorylation of MET, but not with EGFR or ErbB3. Hepatocyte growth factor was also shown to induce resistance to the anti-EGFR antibody cetuximab in lung cancer cells, regardless of EGFR gene status. ${ }^{34}$

Insight into the mechanism of EGF-induced receptor activation came from our recent report on Neu1 sialidase and MMP-9 cross-talk in regulating the EGFR. ${ }^{3}$ The findings in the report on EGFRs also propose an alternative therapeutic approach using OP as a new anticancer agent targeting Neu1 as the key central enzyme regulating this Neu1-MMP-9 cross-talk within the EGFR signaling platform. ${ }^{3}$ Preclinical molecular targeting studies provide the proof-of-mechanism for OP as an effective treatment to inhibit growth and spread of human pancreatic cancer in heterotopic tumor xenografts growing in $\mathrm{RAG} 2 \mathrm{xC} \gamma$ double mutant mice. ${ }^{3}$ It is noteworthy that alternate agents without cross-resistance to platinum or taxanes has been shown to improve the prognosis of platinum-resistant patients. ${ }^{35,36}$ Despite improvements using carboplatin/paclitaxel-based chemotherapy, 30\% of patients with ovarian cancer fail to respond to primary therapy, with a high percentage of the responders relapsing within 1-2 years from the end of primary treatment, and dying of the disease 
within 5 years from their initial diagnosis. ${ }^{37}$ Gemcitabine, on the other hand, has been shown to be an active agent, single and/or in combination with carboplatin and paclitaxel, in the treatment of patients with recurrent ovarian cancer. ${ }^{37}$ Unfortunately, other reports have observed complications to the chemotherapeutics, including hypersensitivity pneumonitis-like patterns in gemcitabine-induced cases $^{38}$ and hypersensitivity reactions to oxaliplatin. ${ }^{39}$ Based on our present results, it is proposed that treatment regimens for triple-negative breast adenocarcinoma could follow a combination therapy of OP at a high dosage with low doses of either cisplatin, 5-FU, paclitaxel, gemcitabine, or tamoxifen. The data in Figure 3 show that for the combination with paclitaxel, OP dosage $\geq 300 \mu \mathrm{g} / \mathrm{mL}$ caused $\sim 95 \%$ reduction in cell viability compared to combination with the other chemodrugs. Based on the fact that hypersensitivity reactions to standard clinical chemotherapeutics are noted complications in cancer patients, ${ }^{38,39}$ it is proposed from our studies that combination therapy of OP and standard clinical chemotherapeutics may have a beneficial effect. Indeed, we have reported that OP significantly inhibited endotoxin lipopolysaccharide-induced $\mathrm{NF} \kappa \mathrm{B}$ activation and the production of nitric oxide and proinflammatory IL-6 and TNF $\alpha$ cytokines in primary and macrophage cell lines. ${ }^{10}$ In another report, we have shown that OP disables the chemoresistance of PANC1 pancreatic cancer cells against cisplatin and gemcitabine alone or in combination in a dose-dependent manner. ${ }^{12}$ The report also showed that OP treatment of PANC1 cells reversed the EMT associated with resistance to drug therapy.

The findings in the current report also reveal an unusual robust and bloody tumor vascularization in heterotopic xenografts of MDA-MB-231 TNBC tumors in RAGxC $\gamma$ double mutant mice (Figure $4 \mathrm{C}$ ). We recently reported that when snail small hairpin RNA (shRNA) A2780 ovarian cancer cells were injected cutaneously, the xenografts of tumors showed no robust bloody tumor vascularization compared with A2780 and A2780 shRNA slug tumors, and the mice were completely devoid of tumor growth and spread to the lungs. ${ }^{13}$ These observations together with another report have shown that the knockdown of snail expression not only suppresses ovarian cancer metastasis but also inhibits primary tumor growth. ${ }^{40}$ Snail not only plays a dual role in controlling the growth and metastasis of ovarian cancer but also functions as a mediator of tumor neovascularization. ${ }^{13}$

It is noteworthy that the transcriptional factor slug is expressed at high levels in normal breast, which may play a role in tubulogenesis. ${ }^{41}$ As an antiapoptotic agent, it could also protect epithelial cells from programmed cell death during ductal lumen formation and breast involution. In breast carcinomas, snail has been linked to tumor progression and invasiveness, ${ }^{41}$ the mechanism(s) which may cause repression of the E-cadherin gene. However, it is unclear how this transcriptional activity by these factors is regulated in vivo. For tumor neovascularization, we have reported that silencing slug in ovarian A2780 cells did not prevent the robust vascularization in $\mathrm{RAGxC} \gamma$ double mutant mice, whereas silencing snail in the A2780 cohort had a profound, complete inhibitory effect. ${ }^{13}$ Collectively, the signaling factors in the pathways that regulate the expression of the snail and slug proteins during different developmental processes have been reported to be tissue- and organism-dependent. ${ }^{42}$ Other reports have shown that snail is associated with cancer invasion and prognosis, ${ }^{43}$ and the overexpression of snail in epithelial Madin-Darby canine kidney (MDCK) cells promotes the EMT toward the invasive phenotype. ${ }^{44}$ Snail expression in MDCK cells had also induced the promoter activity and expression of MMP-9 through the PI3K/ MAPK signaling pathway. For A2780 ovarian and TNBC MDA-MB-231 cells, it is proposed in our studies that snail may play an essential role in tumor neovascularization, the mechanism(s) which may involve the snail-MMP-9 signaling axis in facilitating the signaling paradigm for the activation of growth factor tyrosine kinase receptors to induce Neu1. ${ }^{11,13}$ If MMP-9 is playing a major role in the activation of Neul in complex with EGFR as our data suggest, logistically, snail in inducing MMP-9 in either ovarian A2780 13 or TNBC MDA-MB-231 cells in this report may be the molecular mechanism(s) by which the snail-MMP-9 signaling axis functions in tumor neovascularization. The data have shown that OP, anti-Neu1 antibody, and specific MMP-9 inhibitor treatments of the MDA-MB-231 breast cancer cell line blocked Neu1 activity associated with EGF-stimulation of the live cells. Based on these observations, we propose here that Neu1 might be an intermediate candidate connecting the snail-MMP-9 signaling axis in tumor neovascularization and in promoting the growth and invasiveness of human TNBC.

\section{Conclusion}

Collectively, the snail-MMP-9 signaling axis involvement in tumor neovascularization suggests that the modification of glycosylation on growth factor receptors involves the activation of Neu1. It follows that the molecular-targeting with OP treatment of Neu1 tethered to these receptors would be critically dose-dependent. Given the ability of OP to increase 
E-cadherin expression and decrease $\mathrm{N}$-cadherin expression in TNBC MDA-MB-231 tumors and in ovarian tumors, ${ }^{12}$ TNBC treated with OP may become more adherent to the surrounding tissue and not metastasize as our data indicate (Figure 6). OP treatment strategies are proposed here to take the form of a horizontal approach, of which different oncogenic signaling pathways as well as macrophage-mediated tumorigenesis are targeted with promising therapeutic intent.

\section{Acknowledgments}

This work was supported in part by grants to MR Szewczuk and RJ Neufeld from the Natural Sciences and Engineering Research Council of Canada and private sector cancer funding from the Josefowitz Family to MR Szewczuk. The cancer contents of this report are covered by a Patent Cooperation Treaty international patent application number, PCT/CA2011/050690 (filing November 4, 2011).

We thank Lacey Brodhagen and Alexandra Morris, veterinarian technologists, for their expertise and assistance with the animal work.

\section{Author contributions}

F Alghamdi and S Allison performed the sialidase assay; L Brodhagen and S Allison performed the WST-1 assay; F Haxho performed the immunohistochemistry and the immunostaining for host CD31+ cells in tumor tissues and the liver and lung metastatic tumor analyses; S Abdulkhalek and V Kuta generated and maintained chemoresistant breast cancer cell lines; All authors read and critically revised the manuscript. F Haxho and MR Szewczuk wrote the paper. MR Szewczuk supervised the research design and MR Szewczuk and RJ Neufeld co-supervised F Haxho who prepared the first draft of the manuscript.

\section{Disclosure}

$\mathrm{S}$ Abdulkhalek is a recipient of the RS McLaughlin scholarship, the Ontario Graduate scholarship, and the Canadian Institutes of Health Research Doctoral award (Frederick Banting and Charles Best Canada Graduate scholarship). F Alghamdi was the recipient of the King Abdullah Scholarship from the Ministry of Higher Education, Saudi Arabia. The authors report no conflicts of interest in this work.

\section{References}

1. Rastelli F, Biancanelli S, Falzetta A, et al. Triple-negative breast cancer: current state of the art. Tumori. 2010;96(6):875-888.

2. Top 10 clinical trial failures of 2012 [webpage on the Internet]. Genetic Engineering and Biotechnology News; 2013. Available from: http:// genengnews.com/insight-and-intelligence/top-10-clinical-trial-failuresof-2012/77899765/. Accessed February 3, 2013.
3. Gilmour AM, Abdulkhalek S, Cheng TS, et al. A novel epidermal growth factor receptor-signaling platform and its targeted translation in pancreatic cancer. Cell Signal. 2013;25(12):2587-2603.

4. Jayanth P, Amith SR, Gee K, Szewczuk MR. Neu1 sialidase and matrix metalloproteinase- 9 cross-talk is essential for neurotrophin activation of Trk receptors and cellular signaling. Cell Signal. 2010;22(8): 1193-1205.

5. Alghamdi F, Guo M, Abdulkhalek S, Crawford N, Amith SR, Szewczuk MR. A novel insulin receptor-signaling platform and its link to insulin resistance and type 2 diabetes. Cell Signal. 2014;26(6): 1355-1368.

6. Abdulkhalek S, Amith SR, Franchuk SL, et al. Neu1 sialidase and matrix metalloproteinase-9 cross-talk is essential for Toll-like receptor activation and cellular signaling. J Biol Chem. 2011;286(42):36532-36549.

7. Abdulkhalek S, Guo M, Amith SR, Jayanth P, Szewczuk MR. G-protein coupled receptor agonists mediate Neu1 sialidase and matrix metalloproteinase-9 cross-talk to induce transactivation of TOLL-like receptors and cellular signaling. Cell Signal. 2012;24(11):2035-2042.

8. Amith SR, Jayanth P, Finlay T, et al. Detection of Neu1 sialidase activity in regulating Toll-like receptor activation. J Vis Exp. 2010(43).

9. Amith SR, Jayanth P, Franchuk S, et al. Neu1 desialylation of sialyl alpha-2,3-linked beta-galactosyl residues of TOLL-like receptor 4 is essential for receptor activation and cellular signaling. Cell Signal. 2010;22(2):314-324.

10. Amith SR, Jayanth P, Franchuk S, et al. Dependence of pathogen molecule-induced toll-like receptor activation and cell function on Neu1 sialidase. Glycoconj J. 2009;26(9):1197-1212.

11. Abdulkhalek S, Hrynyk M, Szewczuk MR. A novel G-protein-coupled receptor-signaling platform and its targeted translation in human disease. Res Reports in Biochemistry. 2013;3:17-30.

12. O'Shea LK, Abdulkhalek S, Allison S, Neufeld RJ, Szewczuk MR. Therapeutic targeting of Neu1 sialidase with oseltamivir phosphate $\left(\right.$ Tamiflu $\left.^{\circledR}\right)$ disables cancer cell survival in human pancreatic cancer with acquired chemoresistance. Onco Targets Ther. 2014; 7:117-134

13. Abdulkhalek S, Geen OD, Brodhagen L, et al. Transcriptional factor snail controls tumor neovascularization, growth and metastasis in mouse model of human ovarian carcinoma Clin Transl Med. 2014;3:28.

14. Lehmann BD, Bauer JA, Chen X, et al. Identification of human triplenegative breast cancer subtypes and preclinical models for selection of targeted therapies. J Clin Invest. 2011;121(7):2750-2767.

15. Mazurier F, Fontanellas A, Salesse S, et al. A novel immunodeficient mouse model - RAG2 x common cytokine receptor gamma chain double mutants - requiring exogenous cytokine administration for human hematopoietic stem cell engraftment. J Interferon Cytokine Res. 1999;19(5):533-541.

16. Tan AS, Berridge MV. Superoxide produced by activated neutrophils efficiently reduces the tetrazolium salt, WST-1 to produce a soluble formazan: a simple colorimetric assay for measuring respiratory burst activation and for screening anti-inflammatory agents. J Immunol Methods. 2000;238(1-2):59-68.

17. Cox G, Jones JL, O'Byrne KJ. Matrix metalloproteinase 9 and the epidermal growth factor signal pathway in operable non-small cell lung cancer. Clin Cancer Res. 2000;6(6):2349-2355.

18. Swinson DE, Cox G, O'Byrne KJ. Coexpression of epidermal growth factor receptor with related factors is associated with a poor prognosis in non-small-cell lung cancer. Br J Cancer. 2004;91(7):1301-1307.

19. Woronowicz A, Amith SR, De Vusser K, et al. Dependence of neurotrophic factor activation of Trk tyrosine kinase receptors on cellular sialidase. Glycobiology. 2007;17(1):10-24.

20. Subik K, Lee JF, Baxter L, et al. The expression patterns of ER, PR, HER2, CK5/6, EGFR, Ki-67 and AR by immunohistochemical analysis in breast cancer cell lines. Breast Cancer (Auckl). 2010;4:35-41.

21. Masuda H, Zhang D, Bartholomeusz C, Doihara H, Hortobagyi GN, Ueno NT. Role of epidermal growth factor receptor in breast cancer. Breast Cancer Res Treat. 2012;136(2):331-345. 
22. Meyer AS, Miller MA, Gertler FB, Lauffenburger DA. The receptor AXL diversifies EGFR signaling and limits the response to EGFRtargeted inhibitors in triple-negative breast cancer cells. Sci Signal. 2013;6(287):ra66.

23. Martin HL, Smith L, Tomlinson DC. Multidrug-resistant breast cancer: current perspectives. Breast Cancer (Dove Med Press). 2014;6:1-13.

24. Roberts JG, Chare MJ, Fortt RW, Leach KG, Baum M. Tumour histology and spleen size in women with breast cancer. Clin Oncol. 1980;6(1): 33-38.

25. Roberts JG, Chare MJ, Leach KG, Baum M. Spleen size in women with breast cancer. Clin Oncol. 1979;5(4):317-323.

26. Roberts JG, Wisbey M, Leach KG, Baum M. Proceedings: Spleen size in patients with breast cancer. Br J Cancer. 1975;31(2):262.

27. Roberts JG, Mander AM, Fortt RW, Leach KG, Bligh AS, Baum M. Proceedings: The relationship between spleen size, clinical staging and histological features in breast cancer. Br J Surg. 1975;62(2):159-160.

28. Enger SM, Greif JM, Polikoff J, Press M. Body weight correlates with mortality in early-stage breast cancer. Arch Surg. 2004;139(9):954-958; discussion 958-960.

29. Mehta RS. Dose-dense and/or metronomic schedules of specific chemotherapies consolidate the chemosensitivity of triple-negative breast cancer: a step toward reversing triple-negative paradox. J Clin Oncol. 2008;26(19):3286-3288; author reply 3288.

30. Liedtke C, Mazouni C, Hess KR, et al. Response to neoadjuvant therapy and long-term survival in patients with triple-negative breast cancer. J Clin Oncol. 2008;26(8):1275-1281.

31. Gutierrez MC, Detre S, Johnston S, et al. Molecular changes in tamoxifen-resistant breast cancer: relationship between estrogen receptor, HER-2, and p38 mitogen-activated protein kinase. J Clin Oncol. 2005;23(11):2469-2476.

32. Shou J, Massarweh S, Osborne CK, et al. Mechanisms of tamoxifen resistance: increased estrogen receptor-HER2/neu cross-talk in ER/HER2-positive breast cancer. J Natl Cancer Inst. 2004;96(12): 926-935.

33. Yano S, Wang W, Li Q, et al. Hepatocyte growth factor induces gefitinib resistance of lung adenocarcinoma with epidermal growth factor receptor-activating mutations. Cancer Res. 2008;68(22): 9479-9487.
34. Yamada T, Takeuchi S, Kita K, et al. Hepatocyte growth factor induces resistance to anti-epidermal growth factor receptor antibody in lung cancer. J Thorac Oncol. 2012;7(2):272-280.

35. Bamias A, Bamia C, Zagouri F, et al. Improved survival trends in platinum-resistant patients with advanced ovarian, fallopian or peritoneal cancer treated with first-line paclitaxel/platinum chemotherapy: the impact of novel agents. Oncology. 2013;84(3):158-165.

36. Kelly MG, Mor G, Husband A, et al. Phase II evaluation of phenoxodiol in combination with cisplatin or paclitaxel in women with platinum/ taxane-refractory/resistant epithelial ovarian, fallopian tube, or primary peritoneal cancers. Int J Gynecol Cancer. 2011;21(4):633-639.

37. Fruscella E, Gallo D, Ferrandina G, D’Agostino G, Scambia G. Gemcitabine: current role and future options in the treatment of ovarian cancer. Crit Rev Oncol Hematol. 2003;48(1):81-88.

38. Tamura M, Saraya T, Fujiwara M, et al. High-resolution computed tomography findings for patients with drug-induced pulmonary toxicity, with special reference to hypersensitivity pneumonitis-like patterns in gemcitabine-induced cases. Oncologist. 2013;18(4):454-459.

39. Kim MY, Kang SY, Lee SY, et al. Hypersensitivity reactions to oxaliplatin: clinical features and risk factors in Koreans. Asian Pac J Cancer Prev. 2012;13(4):1209-1215.

40. Jin H, Yu Y, Zhang T, et al. Snail is critical for tumor growth and metastasis of ovarian carcinoma. Int J Cancer. 2010;126(9):2102-2111.

41. Côme C, Arnoux V, Bibeau F, Savagner P. Roles of the transcription factors snail and slug during mammary morphogenesis and breast carcinoma progression. J Mammary Gland Biol Neoplasia. 2004;9(2):183-193.

42. De Craene B, van Roy F, Berx G. Unraveling signalling cascades for the Snail family of transcription factors. Cell Signal. 2005;17(5): 535-547.

43. Mikami S, Katsube K, Oya M, et al. Expression of Snail and Slug in renal cell carcinoma: E-cadherin repressor Snail is associated with cancer invasion and prognosis. Lab Invest. 2011;91(10):1443-1458.

44. Jordà M, Olmeda D, Vinyals A, et al. Upregulation of MMP-9 in MDCK epithelial cell line in response to expression of the Snail transcription factor. J Cell Sci. 2005;118(Pt 15):3371-3385.
Breast Cancer: Targets and Therapy

\section{Publish your work in this journal}

Breast Cancer: Targets and Therapy is an international, peerreviewed open access journal focusing on breast cancer research, identification of therapeutic targets and the optimal use of preventative and integrated treatment interventions to achieve improved outcomes, enhanced survival and quality of life for the cancer patient.

\section{Dovepress}

View the full aims and scopes of this journal here. The manuscript management system is completely online and includes a very quick and fair peer-review system, which is all easy to use. Visit http:// www.dovepress.com/testimonials.php to read real quotes from published authors. 